\title{
Hérnia de Garengeot com apendicite: relato de caso
}

\author{
De Garengeot hernia with appendicitis: case report
}

\author{
Lucas Tadeu Barrak Stangler ${ }^{1}$, Marcos Alexandre Kojima Mori ${ }^{1}$, Ricardo Lobato Chinarelli ${ }^{1}$, \\ Mauricio Alves Ribeiro, ${ }^{2,3}$, Albert Salviano dos Santos ${ }^{4}$, Tiago Bezerra de Freitas Diniz ${ }^{4}$, \\ Bruno de Lucia Hernani ${ }^{2}$, José Gustavo Parreiraa ${ }^{2,5}$, Jose César Assef ${ }^{5,6}$
}

\section{Resumo}

O objetivo deste estudo foi relatar um caso pouco frequente de hérnia femoral associada a apendicite aguda no conteúdo herniário, diagnóstico e tratamento, de paciente atendida no serviço de emergência da Santa Casa de Misericórdia de São Paulo no ano de 2017. As informações foram obtidas através de revisão de prontuário médico, entrevista com a paciente, registro fotográfico dos métodos diagnósticos e cirúrgico, e revisão da literatura. A hérnia de Garengeot consite no achado do apêndice cecal no interior de uma hérnia femoral e ocorre em 0,5 a $5 \%$ dos casos. A sua apresentação associada a um quadro de apendicite aguda é ainda mais rara, ocorrendo em cerca de 0,08 a 0,13\%. A Tomografia Computadorizada (TC) continua sendo o melhor de exame de imagem a ser solicitado em casos de dúvida diagnóstica, podendo auxiliar no planejamento cirúrgico. O tratamento para a hérnia de Garengeot não possui uma padronização definida, existindo diversas abordagens. Em geral, por se tratar de uma urgência cirúrgica, é realizado

1. Acadêmico da Faculdade de Ciências Médicas da Santa Casa de São Paulo - $5^{\circ}$ Ano do Curso de Graduação em Medicina

2. Médico Assistente da Irmandade da Santa Casa de Misericórdia de São Paulo - Serviço de Emergência

3. Professor Instrutor da Faculdade de Ciências Médicas da Santa Casa de São Paulo - Departamento de Cirurgia

4. Médico Residente de Cirurgia Geral da Irmandade da Santa Casa de Misericórdia de São Paulo

5. Professor Adjunto da Faculdade de Ciências Médicas da Santa Casa de Misericórdia de São Paulo-Departamento de Cirurgia

6. Diretor do Serviço de Emergência da Irmandade da Santa Casa de Misericórdia de São Paulo

Trabalho realizado: Faculdade de Ciências Médicas da Santa Casa de São Paulo-Departamento de Cirurgia / Irmandade da Santa Casa de Misericórdia de São Paulo - Serviço de Emergência Endereço para correspondência: Mauricio Alves Ribeiro. Faculdade de Ciências Médicas da Santa Casa de São Paulo. Departamento de Cirurgia - Grupo de Fígado. Rua Mato Grosso, 306 - conjunto 1311 -01239-040 - São Paulo - SP - Brasil. Telefone: (11) 21767270 / E mail: mauricio.ribeiro@me.com

Conflitos de Interesse: Declaramos abertamente não existirem conflitos de interesse na descrição deste relato de caso.

Fomento: Não foram obtidas formas de fomento ou patrocinadores. apendicectomia e reparo da hérnia com a técnica de McVay. O caso relatado e as publicações levantadas trazem à luz a discussão de terapêutica e diagnóstico de uma condição rara que é a hérnia de Garengeot associada à apendicite aguda e evidenciam que quando diagnosticada e tratada adequadamente é capaz de levar a resultados satisfatórios, considerando o alívio sintomático, a resolução de um quadro potencialmente grave como a apendicite aguda e redução nos riscos de novos eventos relacionados ao encarceramento $e$ estrangulamento herniário.

Descritores: Hérnia femoral, Apendicite,

\section{Abstract}

The objective of this study is to report an infrequent case of femoral hernia associated with acute appendicitis in the hernia content, diagnosis and treatment, of a patient admitted at the emergency service of Santa Casa de Misericórdia of São Paulo in 2017. The information was obtained through medical record review, patient interview, photographic record of diagnostic and surgical methods, and literature review. The Garengeot's hernia consists of the finding of the cecal appendix inside a femoral hernia and occurs in 0.5 to $5 \%$ of the cases. Its presentation associated with acute appendicitis is even rarer, occurring in about 0.08 to $0.13 \%$. Computed tomography (CT) remains the best imaging test to be requested in cases of diagnostic doubt, which may aid in surgical planning. The treatment for the Garengeot's hernia does not have a defined standardization, and there are several approaches. In general, as a surgical emergency, appendicectomy and hernia repair are performed with the McVay technique. The case reported and the publications raised bring to discussion the therapeutics and diagnostic methods of a rare condition that is the Garengeot's hernia associated with acute appendicitis. And show that when properly diagnosed and treated it is able to lead to satisfactory results, considering the symptomatic relief, resolution of a potentially severe condition such as acute appendicitis and reduce risks of new events related to incarceration and hernia strangulation.

Keywords: Hernia, femoral; Appendicitis. 


\section{Introdução}

As hérnias femorais consistem de uma protrusão anômala de um órgão ou tecido pelo canal femoral, formando uma tumoração abaixo do canal inguinal. Em alguns casos, bastante raros, pode ocorrer a presença do apêndice dentro do saco herniário, situação conhecida como hérnia de Garengeot. Este trabalho apresenta um relato de caso de uma paciente de 41 anos diagnosticada com Hérnia de Garengeot com apendicite.

\section{Relato de Caso}

Paciente do sexo feminino, 41 anos, deu entrada no serviço de emergência com queixa de dor em região inguinal direita há cerca de 1 mês com exacerbação há 1 semana da admissão; com piora à deambulação e ao esforço físico; febre não aferida e abaulamento local percebido no mesmo período, procurou outro serviço médico sendo liberado com a hipótese diagnóstica de linfonodomegalia. Nega antecedentes mórbidos, nega tabagismo e etilismo. Ao exame físico: bom estado geral, afebril, frequência cardíaca de 82 BPM, eupneica e sem sinais de desconforto respiratório. Abdome plano, flácido, com ruídos hidroaéreos presentes, presença de abaulamento em região inguinal e fossa ilíaca direita associada à hiperemia local e dolorosa à palpação. Exames laboratoriais sem leucocitose, porém com PCR de 4,2 (referência: $\mathrm{PCR}<1$ ).

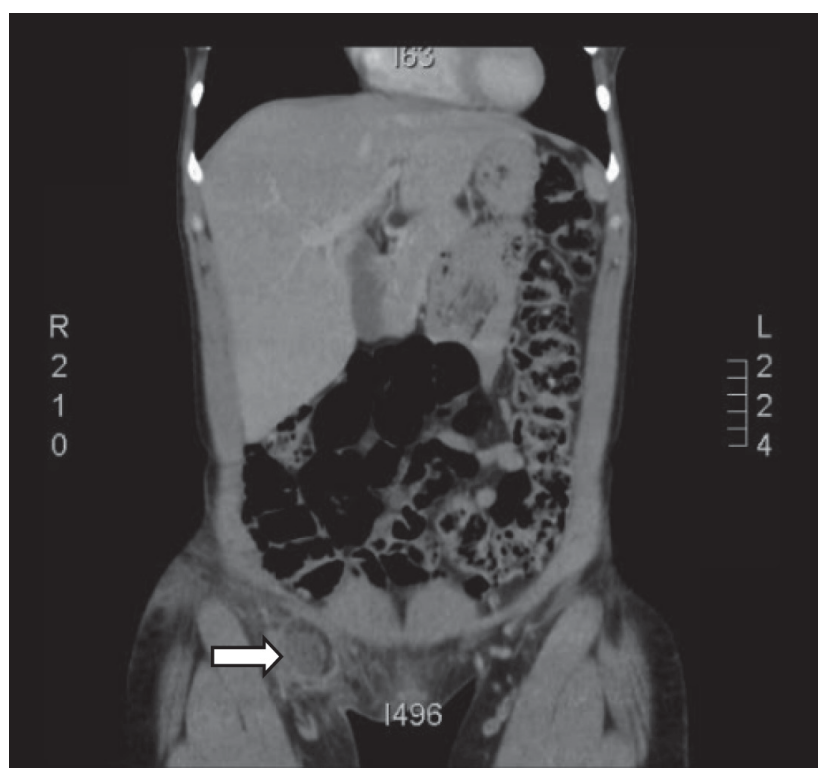

Figura 1 -Tomografia computadorizada em corte coronal evidenciando hérnia femoral (seta)

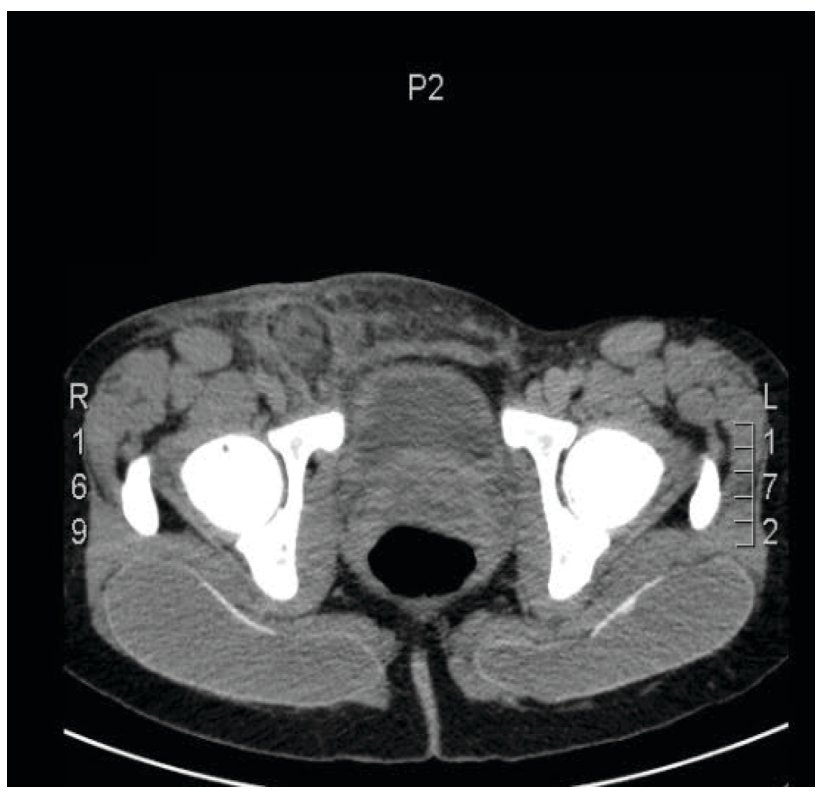

Figura 2 - Tomografia computadorizada em corte axial

Feita hipótese diagnóstica de hérnia femoral estrangulada e indicação de cirurgia.

Realizado a inguinotomia oblíqua, que confirmou não se tratar de uma hérnia inguinal. Realizada a abertura da parede posterior sendo identificada hérnia femoral estrangulada contendo apêndice cecal em seu conteúdo com terço distal necrótico sem perfuração. Realizada a herniorrafia à McVay e apendicectomia.

Evoluiu bem, com alta hospitalar no quinto $\mathrm{PO}$ em vigência de antibioticoterapia com ciprofloxacino $e$ clindamicina e com anatomopatológico evidenciando uma apendicite aguda purulenta com mesoapêndice.

\section{Discussão}

Entre as hérnias abdominais inferiores, ou seja, aquelas que se encontram nos quadrantes inferiores do abdome, há um predomínio de hérnias inguinais, figurando as hérnias femorais uma representatividade de somente $3 \%$ dos $\operatorname{casos}^{(1)}$.

As hérnias femorais são eventos incomuns, sendo a hérnia de Garengeot rara. Foi primeiramente descrita em 1731* pelo cirurgião francês Rene Jacques Croissant de Garengeot. Mas somente em $1785^{* *}$, Hévin realizou a primeira apendicectomia de um paciente com hérnia de Garengeot ${ }^{(2)}$.

No período de 1960 a 2016 foram publicados menos de 100 casos na literatura. $\mathrm{O}$ achado do apêndice cecal no interior de uma hérnia femoral ocorre em 0,5 a $5 \%$ dos casos. Enquanto que a apresentação de uma

* /**APUD Couto HS Jr, de Figueiredo LO, Meira RC, de Almeida Furtado T, Alberti LR, Garcia DP, et al. Treatment of De Garengeot's hernia using De Oliveira's technic: a case report and review of literature. Int J Surg Case Rep. 2016; 26:57-60.(2) 


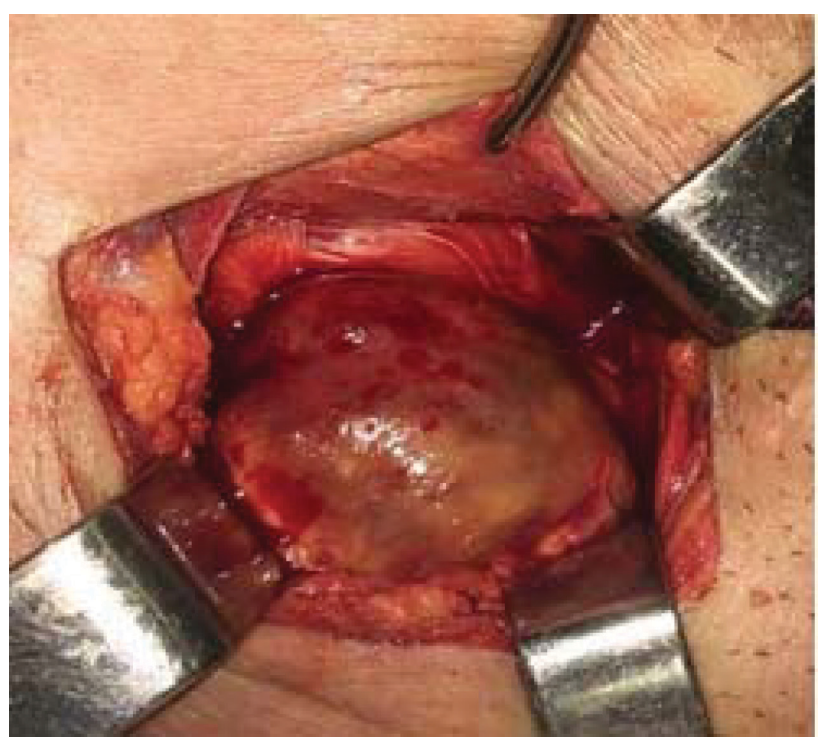

Figura 3 - Imagem do intra-operatório mostrando o saco herniario

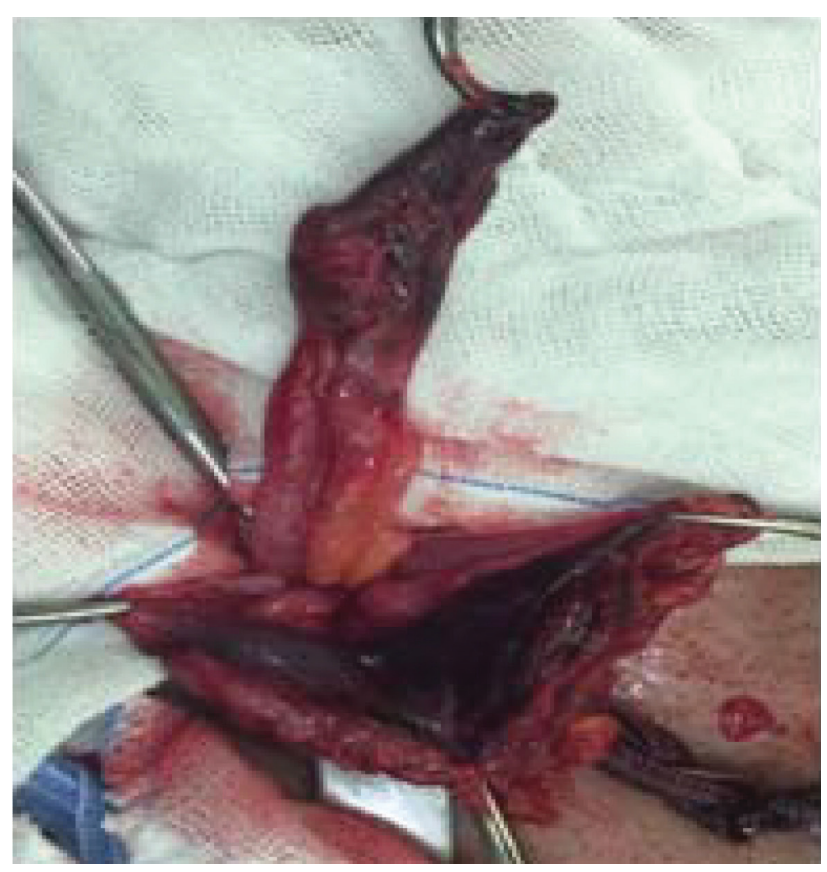

Figura 4 - Saco herniário aberto com apêndice apresentando fundo necrótico

apendicite numa hérnia de Garengeot é ainda mais rara, ocorrendo em cerca de 0,08 a $0,13 \%$ dos $\operatorname{casos}^{(3)}$. Há uma maior prevalência em mulheres pós- menopausa, chegando a uma proporção entre mulheres e homens de 13:1, devido ao predomínio estatístico de hérnia femoral no sexo feminino.

Há controvérsias na literatura em relação à fisiopatologia da hérnia de Garengeot. Alguns autores defendem que um ceco aumentado pode empurrar o apêndice através do saco herniário. Enquanto que outros sugerem que a ocorrência está relacionada com posicionamento anômalo do ceco e/ou do apêndice decorrente das rotações intestinais durante o período embrionário ${ }^{(2)}$. Do mesmo modo, ainda não há um consenso sobre o desenvolvimento da apendicite na hérnia de Garengeot: se ocorre a inflamação do apêndice e então a sua migração para o saco herniário, ou se a inflamação ocorre quando o apêndice já está no saco herniário. A presença de um anel femoral rígido torna as hérnias femorais as hérnias de parede abdominal com maior risco de encarceramento e estrangulamento (entre 5-20\%). Esse processo de compressão extrínseca levando a estrangulamento a isquemia estaria envolvido na fisiopatologia da apendicite. Por esse mesmo motivo, os achados comuns de apendicite não são geralmente encontrados nesta afecção, a patência do anel femoral evita que a inflamação ascenda ${ }^{(3)}$. O achado cada vez mais frequente de apêndices sem sinais de inflamação no interior das hérnias femorais corrobora com a hipótese da inflamação ocorrer após a migração do apêndice ${ }^{(2)}$

Trata-se de uma afecção de difícil diagnóstico, que é feito geralmente no intra-operatório(4). O quadro clínico costuma ser inespecífico e semelhante às hérnias femorais encarceradas. Apresentando-se com dor e desconforto abdominal, associado a achado de abaulamento irredutível, principalmente em região inguinal direita, frequentemente eritematoso e doloroso. O paciente pode evoluir com febre, sinais de abdome agudo obstrutivo e até mesmo choque ${ }^{(5)}$.

O diagnóstico diferencial deve incluir, além da hérnia inguinal, linfadenites, lipomas ou outros tumores de tecidos moles, linfomas e abscessos hipostáticos em processo retroperitoneal e ectasia de veia safena magna $^{(1)}$.

Exames subsidiários podem ser solicitados para complementar a investigação diagnóstica. Exames laboratoriais gerais podem vir com uma leucocitose e PCR aumentados, porém sendo de baixa especificidade, indicando a presença de um quadro inflamatório inespecífico em curso. Os achados radiológicos costumam ser inespecíficos. $\mathrm{O}$ raio- $\mathrm{X}$ de abdome não costuma ser útil para o diagnóstico de hérnia femoral, mas é solicitado na suspeita de obstrução intestinal. A Tomografia Computadorizada (TC) continua sendo o melhor de exame de imagem a ser solicitado em casos de dúvida diagnóstica, auxiliar no planejamento cirúrgico $^{(3,6)}$, mas não altera a indicação cirúrgica de uma hérnia estrangulada. Mas mesmo assim, com uma taxa de diagnóstico pré-operatório de $44 \%$. Achados típicos incluem densidade intramural no interior de um saco herniário encarcerado associada a uma leve distensão de alças intestinais ${ }^{[4]}$. Em alguns casos é possível visualizar uma estrutura tubuliforme circundada por tecido gorduroso projetada abaixo do ceco 
no saco herniário. Esses achados têm $98 \%$ de sensibilidade e especificidade para diagnosticar ou excluir apendicite na hérnia femoral. A ultra-sonografia (USG) não costuma ser solicitado para diagnóstico de hérnia femoral, com apenas um caso descrito diagnosticado usando o USG(6).

O tratamento para a hérnia de Garengeot não possui uma padronização definida, existindo diversas abordagens, possivelmente devido aos poucos casos descritos dessa doença. Em geral, por se tratar de uma urgência cirúrgica, é realizado apendicectomia e reparo da hérnia com a técnica de McVay ${ }^{(2-3)}$.

Entre as complicações pós cirúrgicas mais comumente relatadas após o reparo da hérnia de Garengeot temos a infecção de ferida, ocorrendo em até $1 / 3$ dos pacientes, deiscência de suturas, dor vestigial, sepse e choque ${ }^{(7)}$.

\section{Conclusão}

A partir dos fatos elucidados acima conclui-se que a Hérnia de Garengeot é uma entidade patológica rara e de difícil diagnóstico clínico, sendo na maioria das vezes feito no intra-operatório. Dessa forma, o cirurgião deve estar ciente desta condição e fazê-la presente em sua lista de diagnósticos diferenciais em casos de dor abdominal baixa associada a abaulamentos na região inguinal.

\section{Referências}

1. Bidarmaghz B, Tee CL. A case of De Garengeot hernia and literature review. BMJ Case Rep. 2017 Sep 7; 2017. pii: bcr-2017220926.

2. Couto HS Jr, de Figueiredo LO, Meira RC, de Almeida Furtado T, Alberti LR, Garcia DP, et al. Treatment of De Garengeot's hernia using De Oliveira's technic: a case report and review of literature. Int J Surg Case Rep. 2016; 26:57-60.

3. Kalles V, Mekras A, Mekras D, Papapanagiotou I, Al-Harethee W, Sotiropoulos G, et al. De Garengeot's hernia: a comprehensive review. Hernia. 2013; 17(2):177-82.

4. Valdesde Anca A, Martin-Álvarez JL, Marin-Campos C, GarciaSanz I, Delgado-Valdueza J. Apendicitis aguda perforada em una hérnia femoral incarcerada. Una rara forma de presentacion de una hérnia de Garengeot. Rev Hispanoam Hernia. 2018; 4(3): 123-6.

5. Talini C, Oliveira LO, Araújo AC, Netto FA, Westphalen AP. De Garengeot hernia: Case report and review. Int J Surg Case Rep. 2015; 8C:35-7.

6. Sinraj AP, Anekal N, Rathnakar SK. De Garengeot's Hernia - a diagnostic and therapeutic challenge. J Clin Diagn Res. 2016; 10(11):PD19-PD20.

7. Piperos T, Kalles V, Al Ahwal Y, Konstantinou E, Skarpas G, Mariolis-Sapsakos T. Clinical significance of de Garengeot's hernia: a case of acute appendicitis and review of the literature. Int J Surg Case Rep. 2012; 3(3):116-7.

Trabalho recebido: $20 / 10 / 2017$

Trabalho aprovado: 07/03/2018 